\title{
ARTICLES
}

\section{Pedagogy in Cyberspace: The Dynamics of Online Discourse}

\section{Cindy Xin and Andrew Feenberg}

Abstract

This article elaborates a model for understanding pedagogy in online educational forums. The model identifies four key components. Intellectual engagement describes the foreground cognitive processes of collaborative learning. Communication processes operating in the background accumulate an ever richer store of shared understandings that enable the forward movement of the conversation. The collaborative process requires a moderator to coordinate communication and learning in a group. The moderator in online education is usually a teacher who shares knowledge in the process of leading discussion. Finally, a successful discussion generates intrinsic motivations to participate, which keep the discussion going. This framework is designed to bring out the complexity of online discussion and to provide a basis for advising teachers and evaluating applications and software.

Résumé

Cet article élabore un modèle pour comprendre la pédagogie associée aux forums éducationnels en ligne. L'engagement intellectuel décrit les processus cognitifs d'avant-plan de l'apprentissage collaboratif. Les processus de communication fonctionnant en arrière-plan emmagasinent pour leur part des compréhensions partagées encore plus riches qui permettent de faire avancer la conversation. Le processus collaboratif requiert un modérateur pour coordonner la communication et l'apprentissage dans le groupe. En éducation en ligne, le modérateur est habituellement un enseignant qui partage des connaissances tout en menant la discussion. Finalement, une discussion réussie génère des motivations intrinsèques à participer qui soutiennent la discussion. Ce cadre de référence est conçu de manière à faire ressortir la complexité des discussions en ligne et pour offrir une base afin de conseiller les enseignants, et évaluer les applications et les logiciels.

\section{Introduction}

In this introduction we characterize the problem of online pedagogy in terms of an ideal of effective discussion we call "engaged collaborative 
discourse." The methodology employed in this article is also laid out in this section.

\section{Context and Purpose of the Study}

Most of the new tools and practices employed in online education are electronically mediated versions of familiar pedagogical techniques. This is true of online discussion in asynchronous Web forums, an activity that resembles face-to-face classroom discussion. However, there are significant differences between written and oral forms of engaged collaborative discourse. The first purpose of this article is to explain the implications of these differences for pedagogy in cyberspace.

As the principal form of computer-supported human interaction in online education, discussion plays a vital role, even more significant for learning than in the face-to-face classroom. Commonly identified benefits include more reflective discussions and wider participation. Students are often more interesting to read online than one would guess from their contributions in the classroom where slow or shy participants are overshadowed by more facile, and not always cleverer, peers. Teachers also often find that they are better at leading a written discussion, with time to reflect on students' ideas before preparing careful responses.

But managing online discussion is rather more difficult and time-consuming than might be expected on the basis of the loose analogy with the classroom. Online discussion is paradoxical. It consists in a flow of relatively disorganized improvisational exchanges that somehow achieve highly goal-directed, rational course agendas. Despite the apparent incoherence of online talk, participants have established norms that regain the coherence and personal character of conversational interaction (Herring, 1996, 1999). A conceptual model of this phenomenon must account for both aspects-apparent chaos and order; or rather it must show how the one is in fact an aspect of the other as a process of knowledge construction that combines the informal logic of conversation with the formal rationality of academic discourse. The second purpose of this article is, therefore, to explain online discussion in all its complexity without simplifying it to make it fit a more coherent pattern than it in fact exhibits.

The pedagogical issues we explore are situated in a larger context. Human interaction in online education has been underemphasized and undervalued by the major commercial players in the field (Hamilton \& Feenberg, in press). A decade of experience with learning management systems originally designed to showcase branded, saleable courseware has left many educators skeptical of the value of online education. Products such as WebCT and Blackboard do include Web forums, but not enough attention has been paid to their design and less to training faculty to use them effectively. Perhaps a better understanding of the dynamics of 
learning in asynchronous forums can contribute to overcoming this bias and refocus efforts in online education on the teacher-student relationship.

\section{The Complexity of Online Discussion}

By engaged collaborative discourse we mean group dialogue in pursuit of shared understanding and convergence. The term engaged is used here to emphasize that the participants interact with each other around substantive issues. In our view, engaged collaborative discourse is the best use of online forums for educational purposes. It should play a significant role in both blended and distance learning. However, we do not claim that it is the typical or standard practice of online educators and learners. It is a challenging and time-consuming activity for teachers and students, but well worth the effort.

Like its face-to-face counterpart, online discussion seamlessly combines many speech acts in each utterance. For example, acknowledging receipt of a message carries at least two kinds of information back to the writer: information about the material process of communication-the message got through; and information about the human relations of communication-someone noticed the message and judged it acceptable. If the exchange is semantically rich enough, content-related information may also be conveyed by the response, advancing the communication process in which the interlocutors are engaged. These interactions have a further dynamic import: writing a message that is delivered and accepted encourages further activity in the forum. Such condensations of discursive functions are no exception to the rule; on the contrary, they are typical of the multilayered complexity of human communication.

In education, the complexity has an additional layer not usually found in other contexts, that is, the construction of knowledge through intellectual exchange in a pedagogical community. The social relations of communication are entangled with the learning process in ways that, though difficult to analyze, are grasped to some degree intuitively by teachers and students who draw on a lifetime of educational experience.

The educational literature does not always reflect this entanglement of human communication. Much of the existing work classifies various communicative actions into one category or another depending on whether the interpreter focuses on the social, instructional, or cognitive aspects of discourse. In fact utterances often serve multiple purposes that can be distinguished analytically. We identify four such layers of communicative interaction in online discussion. They are (a) intellectual engagement, (b) communication and common ground, (c) dialogue and motivation, and (d) group dynamics and leadership. Analytical distinctions such as those we make here are invaluable for understanding the complexity of phenomena; however, they do not always correspond to neat distinctions in 
reality. The important thing is to grasp the relationship between the multiple aspects of the same phenomenon and see clearly the interplay between them all.

In the pages that follow, we discuss the four pedagogically significant layers of online educational discourse in the light of a wide range of studies of various aspects of human communication and learning. None of these studies exhaustively describes all aspects of its complex object. Some aspects have received more attention than others with a consequent overemphasis we hope to correct here.

Intellectual engagement. Intellectual engagement consists in presenting examples, elaborating arguments, criticizing views, defining terms, applying concepts, and so on. These explicit performances form what we call the foreground process. It presupposes implicit background understandings previously established in the communication process or brought to it from the common cultural heritage of the participants. The process of intellectual engagement breaks down into a series of phases as participants in dialog work toward a shared understanding of the issues, if not necessarily general agreement. The progressive development of online discussions through logically connected stages is more thoroughly studied in the literature on critical thinking than other aspects of discussion pedagogy, perhaps because we have well-established ideas about rationality that appeal to common sense and especially to teachers. But the conventional view of rationality is increasingly challenged as excessively formalistic in fields as diverse as science studies and human-computer interaction (Lynch, 1993). We can nevertheless learn something useful from this literature about how teachers and students, relying on their own notions of rationality, work toward ends they recognize as educationally valid.

Communication and common ground. This is an undertheorized aspect of the study of online education. All discussion, whether online or face to face, must proceed on the basis of shared assumptions: a common ground that serves in the background as a basis for mutual understanding. The concepts, assumptions, and methods of argument operative in the foreground discussion are drawn from this common ground. In the course of successful discussion the common ground is continually enlarged and its enlargement verified through a variety of speech acts studied by conversation analysis. Each enlargement authorizes a further advance of the discussion agenda.

Dialog and motivation. Online discussion forums constitute written dialogs and share many characteristics with face-to-face dialog. Dialogic pedagogy goes back at least to Socrates, who led students through appropriate questions to a conclusion they arrived at for themselves. Like a game with alternating moves, dialogic inquiry generates intrinsic motives for participation. These include surprise, suspense, and a sense of ac- 
complishment. We look at these motives from the perspective of dialogical process rather than that of individual participants who join an online discussion for various reasons (e.g., desire to learn, getting academic credit) from their offline life. Little attention has been paid in the literature to these motives and their vital importance for the maintenance of the dialog.

Group dynamics and leadership. Group dynamics proceed through the familiar stages of getting acquainted; testing partners' good will; building familiarity and trust; and bonding around shared tasks, experiences, and crises. These sociological aspects of online discussion have been thoroughly discussed in the existing literature and we do not examine them here (Gunawardena, 1995; Gunawardena \& Zittle, 1997; Rourke, 2000; Rourke, Anderson, Garrison, \& Archer, 1999). Instead, we focus on moderating, the leadership role generally assigned to the teacher although often shared by participations in discussion pedagogy. The dispersion of the participants in space and time and the absence of tacit cues pose special problems that are solved through active leadership. The use of the term leadership here is not in the sense of social psychology where leadership is usually related to management of organization, but rather to refer to the process of facilitating or guiding a collaborative learning process through dialog. In fact we use the terms leadership and moderation interchangeably. Thus to lead in the context of this article is to initiate and sustain dialog and mediate students' learning through the use of a set of moderating functions that we discuss below.

Figure 1 illustrates our model of engaged collaborative discourse, which describes the relations between these four layers. The two basic processes are intellectual engagement and communication. Communication leads to the enlargement of the common ground, represented in the diagram by the gradually enlarged ovals. Intellectual engagement leads to conceptual change for individuals and gradual convergence for the group. Moderating functions mediate between the two. Suspense, surprise, and the sense of accomplishment lead to absorption. These intrinsic motives for participation, sustained by moderating functions, stimulate communication and intellectual engagement. The arrows linking the four components signify the relationships between them.

Below we provide in-depth analyses of each of the four layers and descriptions of the relationship between them.

\section{Cognitive Aspects}

The following three sections develop a model of the cognitive processes through which students construct disciplinary knowledge on the basis of interaction with each other and the teacher. 


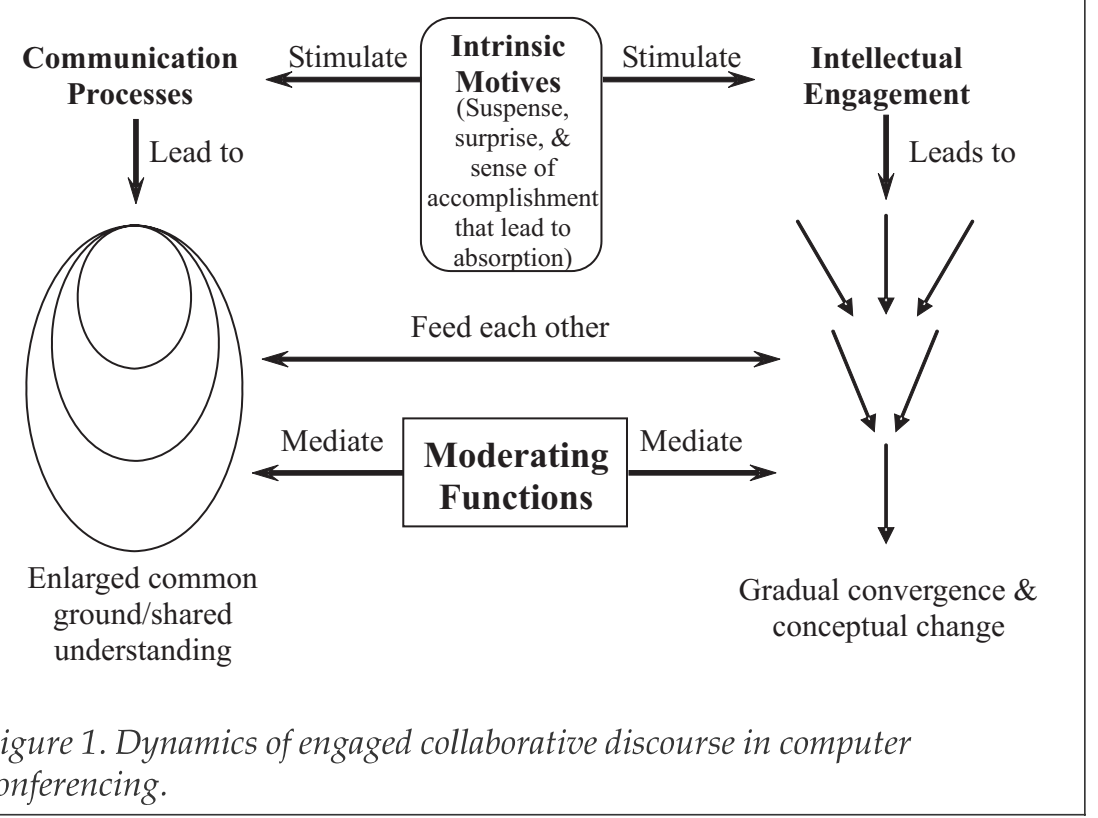

\section{Intellectual Engagement}

The goals of intellectual engagement through collaborative discourse are to achieve convergence at the group level and conceptual change at the individual level. These two outcomes are connected: individual members acquire new concepts and achieve conceptual change through deliberate co-construction of knowledge in the group. This combined process conforms with our understanding of learning since Vygotsky (1962). Developments in cognitive theory, learning theory, and philosophy of science increasingly emphasize the social, culture, and distributed nature of cognition (Hutchins, 1991; Kitcher, 1993; Oatley, 1991; Pea, 1993).

Roschelle (1996) argues that the crux of collaboration is the struggle for convergence through conceptual change. Convergence requires the sharing of common and differing views, the negotiation of varying levels of understanding, visiting and revisiting various horizons, and the gradual fusion of them all (Gadamer, 1982). Research in conversational analysis (Goodwin \& Heritage, 1990; Levinson, 1983) explains how students collaboratively construct increasingly sophisticated approximations to scientific concepts. Roschelle identifies democratic participation, intellectual progress, and gradual convergence as the basic practices of social inquiry that enable scientists to undergo conceptual change. He concludes that in the course of collaborative conversational interaction, students develop 
their own concepts through practices of inquiry similar to those employed by scientific communities.

The concept of convergence raises some significant questions. The usual understanding of the term suggests explicit agreement. This is surely appropriate in a task-oriented group that must reach and implement decisions. Consensus is also a valid pedagogical objective where the material taught consists of facts or scientific theories. However, consensus may be too much to hope for in many discussions in the humanities and social sciences, although some degree of understanding of others' views is usually achievable (Burbules, 1993).

The goal here is to enable the students to grasp the terms of a controversy rigorously, informed by a disciplinary context and concepts. The pursuit of this sort of convergence is heuristic rather than substantive. Thus it is commonplace for teachers to conclude a discussion before everyone is in agreement, once the back and forth of argument has brought out the various positions clearly. This is a pedagogically valid procedure where the aim of education is individual enlightenment rather than practical decision-making or induction into a scientific profession.

Recent educational literature has adopted the premise that successful educational experience must take account of both the learner's personal world and the shared surrounding world. Social context greatly affects the process and outcome of learning. Lipman (1991) notes that a community of inquiry promotes critical thinking. Garrison's and Archer's (2000) collaborative constructivism shows that education involves the complementary activities of individual constructon of meaning and social enculturation.

If learning necessarily involves the two complementary activities of group interaction and personal reflection, how might computer conferencing facilitate and support it? To answer this question, we briefly survey the recent literature on dialog in teaching and critical inquiry.

A variety of contemporary authors have also discussed the pedagogical implications of dialog. Burbules (1993) identifies four types of dialog used in teaching: as conversation, as inquiry, as debate, and as instruction. Gadamer (1982) considers dialog as the primary process through which people achieve mutual understanding. The acquisition of knowledge involves reflecting on various cognitive horizons leading to conceptual change through the fusion of one's own horizon with that of others. In the educational process, fusion is supposed to enlarge the students' horizon to encompass elements of a disciplinary tradition. Bruffee (1999) asserts that college and university teaching is about negotiation at the boundaries between the members of knowledge communities and students who wish to join. The professors' task is to link students' horizons to their intended knowledge communities. 
One major goal of online dialog is to promote critical inquiry (also known as critical thinking) and deep learning (Newman, Johnson, Cochrane, \& Webb, 1997). Critical inquiry is usually described as a process of achieving understanding through logical inquiry or reasoning, critical evaluation, problem-solving, and rational decision-making. Kanuka and Kreber's (1999) study failed to show a relationship between instructional methods and high levels of knowledge construction in the online environment. However, the results of a later study by Kanuka (2005) support the position that text-based Internet communication technologies can facilitate effective learning environments through the use of certain instructional strategies, resulting in the ability to facilitate higher levels of learning.

Garrison (1991) outlines a five-stage model of critical thinking applied to problem-solving in adult learning. The five stages include problem identification, definition, exploration, applicability, and integration. These stages describe the process of initiating interest in a problem; defining problem boundaries; identifying ends and means; exploring, developing, comparing, and structuring new ideas and solutions; critical assessment of ideas; evaluating solutions; and finally, acting on these understandings to validate knowledge. Garrison's model serves as a basis for some important later studies.

Based on Garrison's (1991) original model, a recent study by Garrison, Anderson, and Archer (2001) defines four phases of critical inquiry in computer conferencing: triggering event, exploration, integration, and resolution. The triggering event is an issue or problem presented for discussion. Next, the discussion enters the exploration phase in which the participants shift between individual reflective thinking and public discourse in the group; this phase is characterized by information exchange, brainstorming, questioning, and clarifying. The third phase is integration, described as meaning construction based on the ideas generated in the exploration phase. Integration is characterized by assessing, connecting, and synthesizing ideas and creating solutions. The inquiry concludes with a resolution phase in which the participants implement proposed solutions or test hypotheses by means of practical applications or thought experiments. Participants often continue consensus-building in this phase until ready to move on to a new theme, which starts a new round of four-phase critical inquiry.

Another noted study by Gunawardena, Lowe, and Anderson (1997) identifies five typical phases of negotiation and knowledge co-construction in an online debate among a large group of distance education professionals. The five phases are sharing/comparing of information, discovery of dissonance and insistency, negotiation of meaning and co-construction of knowledge, testing and modification of the proposed synthesis, and agreement/application of newly constructed meanings. In phase 1, par- 
ticipants identify problems, state agreement and disagreement, provide supporting examples, and clarify statements through questions and answers. In phase 2, areas of disagreement are identified and clarified. In phase 3, participants negotiate agreement and compromise and propose integration of metaphors. In phase 4 , participants test a proposed synthesis against existing cognitive schemas, data, and testimony. In phase 5, participants summarize agreement, apply knowledge, and illustrate change through metacognitive statements.

The above three models of Garrison (1991), Garrison et al. (2001), and Gunawardena et al. (1997) represent online knowledge construction as a developmental, incremental, and iterative process. Although the models differ slightly, each depicts a beginning, middle, and end with each phase marking an advance toward increasing intellectual complexity as the group moves from divergence to convergence and the individual members achieve deeper understanding. Thus despite the differences between them, they describe the same general process of development from the loosely connected small talk of the outset to joint discussion of a shared theme to the resolution of disagreements in a convergent conclusion.

We next clarify the underlying cognitive condition of group interaction through which individuals establish a common ground of meanings and cognitive tools enabling joint discourse. Indeed, unless the individuals grasp each other's thoughts and feelings and share a common language, they cannot work together productively. These understandings are often operative in conversation without necessarily appearing as themes of discussion. By contrast, convergence occurs when the group arrives at a single point of view on a subject through explicitly articulated argument. Convergence as mutual agreement or consensus presupposes the more fundamental level of shared language and assumptions employed in the discussion, but it is not identical with this enabling background. The achievement of this sort of community of thought and feeling does not conform to the models of intellectual engagement, but has its own far less logical procedures, which we consider in the next section.

\section{Communication and Common Ground}

Online talk consists of many almost invisible background processes that enable communication to flow. These processes have been largely overlooked in educational theory in the concentration on intellectual exchange in which interlocutors propose ideas and factual assertions and argue more or less logically about their validity. But this foreground process is only possible because an already established common ground of shared preexisting assumptions enables communication in the first place. This is the overlooked basis of online talk.

Stalnaker (1978) describes it this way: 
Roughly speaking, the presuppositions of a speaker are the propositions whose truth he takes for granted as part of the background of the conversation ... Presuppositions are what is taken by the speaker to be the common ground of the participants in the conversation, what is treated as the common knowledge or mutual knowledge. (p. 320)

How does conversation enlarge this common ground? According to Clark and Schaefer (1989), conversations are highly coordinated activities that consist of collective performances by the participants working together. Such performances include the efforts of the current speaker to make sure that he or she is attended to, heard, and understood by the other participants; they in turn must let the speaker know when he or she has succeeded or failed. Understood on these terms, the communication process is not reducible to a logical sequence of propositions. It is a social process in which contingent interactions, improvisations, and negotiations over meaning continually produce the basis for further interaction. The surface logic of educational dialog is underpinned by a different pattern of communicative exchange that makes sense to be sure, but only contextually and as a temporally unfolding process.

In Clark and Schaefer's (1989) model, a "contribution to discourse" (CTD) is defined as a unit of conversation that consists of content specification and content grounding. In content specification the contributor presents a contribution and the partners register it. Content grounding, or simply grounding, is the process by which the contributor and the partners establish the mutual belief that understanding has been achieved. Thus contributions to discourse consist in two essential phases, presentation and acceptance. It is only through carrying out both phases successfully that the participants collectively build their common ground.

To support their CTD model, Clark and Schaefer (1989) identify five main types of evidence of understanding or acceptance. A is the presenter, and $\mathrm{B}$ is the receiver.

1. Continued attention: B shows he or she is continuing to attend and therefore remains satisfied with A's presentation.

2. Initiation of relevant next contribution: $B$ starts in on the next contribution that would be relevant at a level as high as the current one.

3. Acknowledgment: B nods or says "uh huh," "yeah," or the like.

4. Demonstration: B demonstrates all or part of what he or she has understood A to mean.

5. Display: B displays verbatim all or part of A's presentation. (p. 267)

These types of evidence are ranked roughly from the weakest to the strongest. Continued attention or initiation of relevant next contribution 
offers the least evidence of understanding. Acknowledgment, demonstration, and display each offer increasingly strong evidence of understanding.

Repair is an essential discursive subprocess that consists of correcting misunderstandings. It is important to meaning-making and a necessary ingredient in Clark and Schaefer's (1989) model. To achieve grounding consistently, the participants must not only repair any trouble they encounter but also take positive steps to establish understanding and avoid trouble in the first place. This is more difficult online than face to face.

With significant modifications, the CTD model suggests a framework for analyzing discourse in computer conferencing.

First, the model is based on the simplest case of a conversation between two participants. The process of many-to-many discourse, real-time or asynchronous, face to face or online, is far more complex because understanding is reached gradually between increasing numbers of participants. Group discussion in education, therefore, relies on a moderator to ensure proper turn-taking and keep the process advancing in the right direction. This role is performed through the exercise of what we call moderating functions, which is discussed in detail below.

Second, the CTD model describes face-to-face conversation. Online, without visual and verbal cues, and with participants communicating asynchronously, the troubles that call for repair may not be identified promptly. Repair, therefore, also calls for the exercise of online leadership to ensure the proper flow of the discussion.

Third, almost all the examples given to illustrate the CTD model are drawn from brief, trivial daily conversations. Engaged collaborative discourse concerns deeply structured meanings related to a definite subject matter and explored over a considerable period. Although the fundamental processes of the CTD model hold for this type of discourse, it is necessarily somewhat different in structure.

Finally, although the basic concept of presentation and acceptance holds, not all the evidences of understanding identified in the CTD model apply to computer conferencing; hence their relative strength is modified. We examine below the five types of evidence in this context.

Continued attention in a face-to-face conversation tells the presenter $\mathrm{A}$ that the receiver $B$ has understood what $A$ has said; silence signifies that $A$ can be confident of having succeeded for current purposes and should continue with the presentation. However, silence online is often a puzzle for the presenter, a source of communication anxiety (Feenberg, 1989). It is not clear whether it signifies agreement, polite disapprobation, indifference, or perhaps even complete absence from the conference. Only explicit evidence of understanding counts online. 
For various reasons, display is less effective online than face to face. Displaying or repeating the contributor's exact words does not by itself show comprehension because all text may be mechanically retrieved.

Initiation of a relevant next contribution can supply valid evidence online, albeit less effectively than in face-to-face conversation. The problem is timing. Conversation analysis implicitly assumes the synchronicity of face-to-face talk. It is obvious in this context that the relevant next contribution must be spoken within a short period to count as acceptance. Beyond this short period, it will appear as another original presentation. Because these effects of timing cannot be unambiguously achieved in asynchronous discourse online, this form of acceptance is not always successful.

The strongest evidence of understanding online, the only one that is really unambiguous, is reformulating the contributor's presentation in the interlocutor's own words or correctly applying learned concepts in new situations. This places a considerable burden on the interlocutors: they must interact explicitly around the content of each others' messages to be assured of mutual understanding. But this burden is useful in education: the more deeply the participants interact, the more successful they will be in advancing the agenda of the course and achieving individual conceptual change.

Traditional conversation analysis yields many valuable insights into the process of face-to-face talk. Recently, it has become a highly relevant qualitative research approach for examining educational phenomena related to computer-mediated discourse (Mazur, 2003). Mazur's comprehensive article in the Handbook on Research for Educational Communications and Technology explores the theoretical and methodological issues for researching the structures, processes, and meaning of online talk. With the modifications suggested in this article, the insights we identify can be applied to understanding the production of the common ground of online groups.

Considered dynamically, the three models of collaborative discourse and critical inquiry presented above suggest a progressive development in which the end of each cycle of learning becomes the beginning of the next cycle. The CTD model offers insight into this process: communication deepens through a series of attempts to explain, verify, repair, and confirm the subject of discussion; each cycle begins with an enlarged common ground resulting from the shared understanding and group convergence so far achieved. New knowledge artifacts are shared in the group at the end of each cycle of dialog; these shared objects must be appropriated by the individuals for them to engage in the collaborative activities of the next cycle. Intellectual engagement draws on the common ground in the pro- 
cess of sharing, questioning, negotiating, testing, and synthesizing knowledge.

\section{Relation Between Intellectual and Communicative Processes}

We turn now to the relation between this background process and the foreground process of intellectual engagement.

To describe intellectual engagement and the many-to-many communication process, we present a three-phase discourse model that takes into account the complexity of building common ground and shared understanding in a group (see Figure 2). We call these phases topic initiating, multi-logue, and common-logue. Each phase has foreground and background aspects. Intellectual engagement constitutes the foreground that enables individual conceptual change and group convergence. Communication processes constitute the background that builds common ground as shared understandings are deployed in discussion.

In Figure 2, squares represent participants, circles represent contributions, and ovals the common ground. The overlapping circles in the last stage represent the part convergence achieved through the discussion.

Although we present intellectual engagement and communication as developmental processes that go through phases from beginning, middle to the end, we do not mean to imply that online discussion typically follows a neat linear process. We describe a general development trend that depends on the will of students and teachers to proceed more or less methodically toward some sort of shared conclusion. However, like everyday conversation in a group, online discussion is an iterative process with frequent digressions and complicated repair processes. Below we describe the model in more detail.

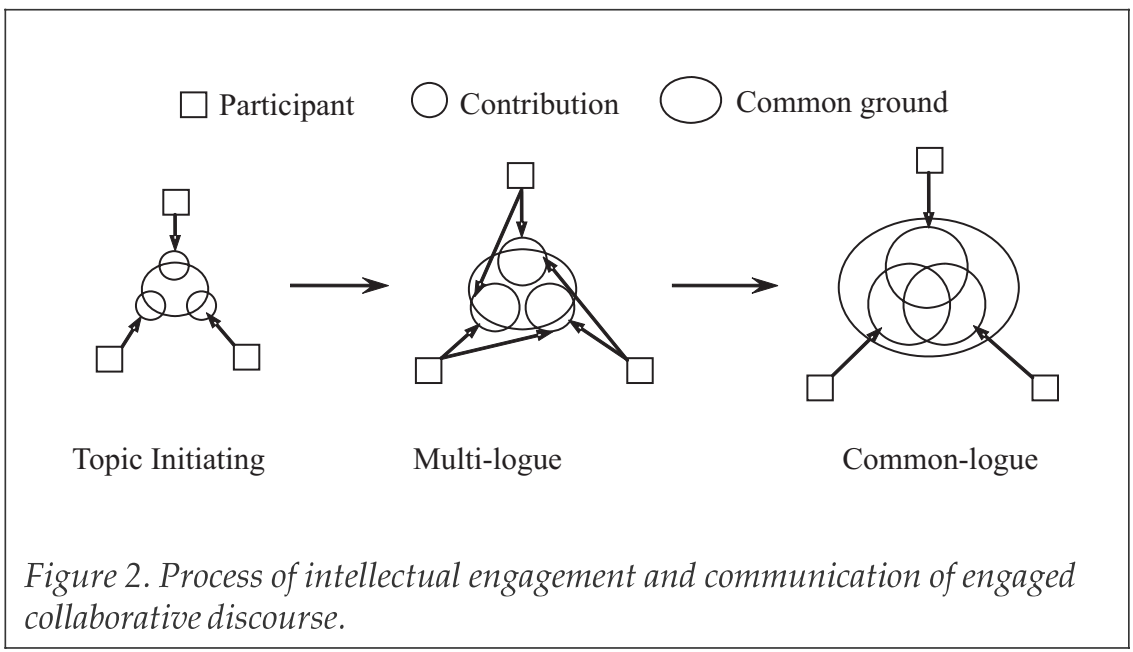




\section{Phase 1. Topic initiating}

Foreground. During the initial phase, a topic (e.g., a problem or an issue) is proposed for discussion, and individual participants respond by presenting their own thoughts and feelings, personal observations, and examples. Intellectual engagement in this early phase does not generally aim at achieving agreement, but rather at defining terms and problem boundaries, clarifying statements and context, and proposing approaches.

Background. In the course of these activities, participants begin to identify common ground among the ideas, assumptions, and experiences each has brought to the discussion. The common ground in this phase may not extend much beyond the shared values and experiences the participations bring to the discussion from their offline lives. The scope for misunderstanding is considerable.

Contributions to the discussion in this phase have an implicit purpose that may not be fully apparent: testing the limits of shared understanding to establish the initial common ground of the group. By the end of this phase, participants should have a feeling that they can deploy some basic concepts without being misunderstood. Equal access and distributed participation are essential in the initiating phase so that as many participants as possible can engage in this process of testing basic understandings.

\section{Phase 2. Multi-logue}

Foreground. The process of intellectual engagement in this phase leads to deepened understanding of how best to resolve the problem posed in the topic-initiating phase. The multi-logue phase begins conceptual change at the individual level. Convergence of opinion among informal subgroups is forming gradually, and on at least some issues, consensus is reached among the group as a whole. Discussion is advanced as the teacher introduces disciplinary concepts and methods and tests understanding of these new ideas. During this second phase, the participants agree and disagree, clarify and elaborate; reflect and organize; and attempt to justify ideas, positions, and solutions put forth in the preceding phase.

Background. Corresponding to these activities, the common ground is enlarged in uneven patterns throughout the group. In this phase, individuals' horizons are considered and challenged, sometimes strengthened, sometimes broken down, but eventually extended. Elements of the disciplinary tradition are absorbed into this process and offer new cognitive tools. This process consists of many rounds of presentation and acceptance as defined by Clark and Schaefer (1989). But despite the apparent linearity of their model in our simplified presentation above, the multi-logue does not necessarily follow a smooth path. In computer conferencing, one often observes multiple concurrent presentations and acceptances or complex sequences of presentation, rejections, repairs, and then acceptances. By the 
end of this phase, understandings well beyond the initial common ground are established in the group as a whole.

\section{Phase 3. Common-logue}

Foreground. Once the group is equipped with considerable shared knowledge artifacts and has clarified the terms of its discourse, a new phase of intellectual engagement can begin. This phase leads to relative convergence on a decision and/or solution through synthesis and integration of established arguments on the basis of the common ground. As we have seen, in some fields, the pursuit of agreement is more important than its achievement. It is this process that finally leads individual learners to the acquisition of new knowledge.

Background. This, then, is the final phase that leads to a general fusion of horizons embracing both the individual students and the disciplinary tradition represented by the teacher (Gadamer, 1982). In this phase, the common ground is extended to embrace the entire group in the course of deploying the existing shared cognitive resources to resolve the issues at hand. Even where not everyone comes to the same conclusions, learning takes place in the process of discussion of differences. Shared understanding rather than unanimous agreement is thus another possible outcome of the fusion of horizons.

As this description shows, the two basic processes-intellectual engagement and communication-are intertwined and inseparable. They are aspects of one and the same process of online discussion. In the foreground, the group strives for conceptual change and convergence. In the background, participants sustain the discourse and build its common ground. The common ground is a resource that supplies shared knowledge artifacts that the participants employ in articulating their positions and developing solutions. In turn, the results of knowledge construction are deposited in the background and contribute to the common ground mobilized in the next stage of the discussion. This reciprocal interaction forms a mutually supporting system as the outcomes of communication aid the process of the knowledge construction and vice versa.

\section{Social Aspects}

Here we discuss online leadership and motivation, the social aspects of engaged collaborative discourse that are most challenging for teachers. We identify motivations to learn that are generated by the dynamic of discussion and show how effective moderating can help to sustain the conversation and advance it toward pedagogical objectives. 


\section{Dialog and Motivation}

In the Meno, Socrates takes a slave boy through the steps of a geometric proof. The dialog exemplifies a pedagogical approach that works by questioning the learner at just the level of difficulty that is appropriate to his or her current understanding. The student is helped to make active mental connections, often called knowledge construction by educational theorists, without forced and premature conceptual leaps.

In order to question at the right level of difficulty, the teacher must assess the gap between the "actual developmental level as determined by independent problem solving" and the "level of potential development as determined through problem solving under adult guidance or in collaboration with more capable peers" (Vygotsky, 1978, p. 86). Vygotsky defines this gap as the "zone of proximal development." Learning involves the teacher in dialog with the student, building up levels of support appropriate to the student's state of readiness and that can be gradually withdrawn as understanding of the subject matter matures. This is described as scaffolding (Wood, 1999).

Activity in the zone of proximal development is arduous, but emotionally rewarding. Similarly, dialog is not merely a cognitive process, but involves the whole person. Everyone who has participated in a lively discussion recalls the excitement of interaction and discovery that stimulates an unusually high degree of alertness and involvement. This is no less true online where the excitement generated by the discussion is even more essential to maintaining participation than it is in face-to-face dialog. We call the motivations arising from the nature of dialog intrinsic in contrast to such extrinsic motivations as a requirement to participate. Intrinsic motivations include the suspense provoked by waiting for responses, the surprise of unexpected interventions, and the sense of accomplishment that comes from recognition by others and the successful grasp of new ideas.

Sports and games offer metaphors for the peculiar sociability sustained by these motivations. The players aim at a goal external to the play such as winning, but at each round of play, their moves are provoked by and provoke responses for intrinsic reasons such as the excitement of taking the ball away from an adversary. The game consists in the back and forth of move and counter-move with winning as the horizon under which the interactions take place. In reality, dialog resembles relaxed volleying rather than a serious match. One wants one's volleys returned, and the aim is not winning, but improving one's game. Similarly, each message in educational dialog fulfills a double goal: to communicate a content and to evoke further response. The true pleasure of playing at online discussion consists in making moves that keep others playing (Feenberg, 1989; Feenberg \& Xin, 2002). 
Goffman (1961) employs the terms absorption and engrossment to describe the force that draws people into a game. Collaborative discourse online has a comparable fascination. The unfolding logic of a discussion engages us to the point where we are completely absorbed in the action and eagerly anticipate the next move. Engrossment is due to the enjoyment of the process of dialog for its own sake. What enables online community in education is not so much bonds of sentiment formed from personal intimacies, but the deeply satisfying pleasure of engrossment in a dialog game. This in turn creates the emotional bond of community (Xin, 2002).

Effective leadership by a moderator is essential to keep the participants absorbed and the game going. The moderator defines and models communication and behavioral norms that function as the equivalent of the rules of play. The moderator must continually ensure that these norms are observed to safeguard the flow of the discussion. We have more to say about moderating below.

\section{Group Dynamics and Leadership}

For years there has been a demand for a shift from teacher-centered to student-centered learning. This is best characterized in the popular slogan calling for the teacher to be "a guide on the side" instead of "a sage on the stage." Many educators celebrate computer conferencing as an ideal environment for implementing student-centered learning.

But can a facilitator who remains on the sidelines achieve the goals of education? Dewey (1938), who is often identified with the studentcentered approach, eloquently argues that "the mere removal of external control" cannot guarantee "the production of self-control" (pp. 62-64). Learning occurs, Dewey believes, when teachers exercise control indirectly through "work done as a social enterprise in which all individuals have an opportunity to contribute and to which all feel a responsibility" (p. 56). Similarly, neo-Vygotskians believe that individual learners construct conceptual knowledge through guided instruction rather than independent exploration alone (Kozulin, 2003; Merrill, 1992). This concern applies particularly online where the communication process is fragile and unfamiliar to both teachers and students. Because of this, scholars and teachers have recognized that leadership is essential in achieving effective discourse (Anderson, Rourke, Garrison, \& Archer, 2001; Berge, 1995; Feenberg, 2000; Hiltz \& Turoff, 1978; Rossman, 1999).

Having said this, we need to forestall a possible misunderstanding. By leadership we do not mean a one-sided emphasis on the authority of the teacher. Leadership activities in any group, including online classes, can be more or less shared among the members. Of course students expect teachers to play the main leadership role, and this is usually necessary for 
successful teaching. However, discussion classes work best when many participants lead in small ways under the general direction of the teacher.

Some of the most important functions of leadership include making participants feel welcome, introducing them to each other, encouraging them to work together harmoniously, and resolving personal conflicts or misunderstandings. These functions are common to all task-oriented groups, whether on or off line. However, education involves specific activities that combine social and cognitive functions of leadership. We focus on these activities here.

Extensive disciplinary knowledge differentiates teachers from students. In this respect, there is little difference between teaching in a classroom and teaching online. However, introducing disciplinary knowledge in computer conferencing must contribute to the discussion without interrupting it. The best way to do this is not obvious, but requires conscious pedagogical choice.

Teachers often introduce too much or too little content to sustain the discussion. Too much content turns the discussion into a lecture. In the classroom, the lecturer must perform and entertain to hold students' attention. Although it is one-person show, much interaction between the lecturer and the audience takes place through implicit nonverbal communication. Online, excessive presentation by the teacher leaves little chance for the content to be absorbed through negiotiation and often prevents students from contributing.

At the other end of the spectrum, if the teacher introduces too little content, he or she ends up behaving like a student or withdrawing from the discussion. In either case, the students either stop talking altogether or carry on a bull session in which they simply converse according to the whim of the moment and ramble from topic to topic. However interesting and informative such bull sessions may be, students lose the opportunity to be introduced to the disciplinary tradition of the teacher's knowledge community.

To be effective in online discussion, the teacher must be sensitive to the dynamic of the conversation, inject expert knowledge when appropriate, and connect students' contributions to the field. These tasks must be interwoven with the social and communicative functions of moderating.

Several studies provide insights into moderating. Feenberg (1989) emphasizes the differences between online and face-to-face discussion from a communication-theoretic perspective and highlights the specific communicative performances that belong to the online moderating role. He argues that managing a successful conference requires strong, but not overbearing leadership through complex communicative interventions. His early article defines a set of moderating functions and classifies them under three categories as follows. 
Contextualizing functions. These functions provide a shared framework of rules, roles, and expectations for the group.

Monitoring functions. These functions help participants know if they have successfully followed the group's norms and fulfilled the expectations laid down for them.

Meta functions. These functions have to do with the management of process and content and include such activities as repairing communication links, summarizing the results of intellectual engagement, and assigning specific roles to participants.

Berge (1995) proposed a widely used classification of facilitating activities under four categories: pedagogical, social, managerial, and technical. A recent contribution to the literature by Anderson et al. (2001) presents a model for assessing "teaching presence" in online courses. Teaching presence is defined as the extent to which the participantsespecially the teacher-are able to design educational experiences, facilitate discourse, and provide direct instruction. Many of the role categories in these two later studies resemble Feenberg's (1989) moderating functions. However, these studies offer additional insights. Based on a synthesis of the three models, additions are made to Feenberg's original scheme.

A revised version of the moderating functions is presented in Table 1 (Xin, 2002; Feenberg \& Xin, 2003).

The two-sidedness of moderating - social and cognitive-is the key to online pedagogy.

\section{Moderating Functions in the Dynamics of Engaged Collaborative Discourse}

Effective moderating addresses online leadership: the central problem of computer conferencing. First, as explained above, it mediates between students' understanding of the subject matter and a disciplinary tradition so as to enable them to become members of the knowledge community they are studying to join.

Second, moderating mediates each of the two underlying processescommunication and intellectual engagement-and enables the advance from one stage to the next. On the communication side, it sustains the social relations of communication and mutual understanding in the group. Because the messages that perform moderating functions often encapsulate cognitive contributions, the effective use of these functions fulfills an intellectual as well as a communicative role.

Third, on the cognitive side, communication and intellectual engagement are intertwined and inseparable. However, connecting the two processes is not always easy. Intellectual engagement depends on the common ground identified in earlier discussions. But as we have seen, acceptance, which is essential to the production of common ground, is more 
Table 1

Summary of Moderating Functions

\section{Contextualizing functions}

1. Opening discussions. The moderator must provide an opening comment that states the theme of the discussion and establishes a communication model. The moderator may periodically contribute "topic raisers" or "prompts" that open further discussions in the framework of the forum's general theme.

2. Setting the norms. The moderator suggests rules of procedure for the discussion. Some norms are modeled by the form and style of the moderator's opening comments. Others are explicitly formulated in comments that set the stage for the discussion.

3. Setting the agenda. The moderator manages the forum over time and selects a flow of themes and topics of discussion. The moderator generally shares part or all of the agenda with participants at the outset.

4. Referring. The conference may be contextualized by referring to materials available on the Internet, for example, by hyperlinking, or offline materials such as textbooks.

\section{Monitoring functions}

5. Recognition. The moderator refers explicitly to participants' comments to assure them that their contribution is valued and welcome, or to correct misapprehensions about the context of the discussion.

6. Prompting. The moderator addresses requests for comments to individuals or the group. Prompting includes asking questions and may be formalized as assignments or tasks. It may be carried out by private messages or through public requests in the forum.

7. Assessing. Participants' accomplishment may be assessed by tests, review sessions, or other formal procedures.

\section{Meta functions}

8. Meta-commenting. Meta-comments include remarks directed at such things as the context, norms, or agenda of the forum; or at solving problems such as lack of clarity, irrelevance, and information overload. Meta-comments play an important role in maintaining the conditions of successful communication.

9. Weaving. The moderator summarizes the state of the discussion and finds threads of unity in the comments of participants. Weaving recognizes the authors of the comments it weaves together and often implicitly prompts them to continue along lines that advance the conference agenda.

10. Delegating. Certain moderating functions such as weaving can be assigned to individual participants to perform for a shorter or longer period.

complex in a group. To promote acceptance, the moderator explicitly thematizes the common ground established by the ongoing process of intellectual engagement so that the group can confidently take for granted its own shared horizon. This enables students to relate their individual horizons to those of others and guides the collective actions of the group in the next phase of intellectual engagement. Moderating thus ensures that the building of a common ground aids problem-solving and convergence, and the construction of knowledge furthers the enlargement of the established common ground.

The moderating functions play slightly differing roles in various phases in the unfolding of the online discussion. In the topic-initiating phase, opening comments define the topics of discussion and invite the participants to share their initial observations, thoughts, and feelings. Setting norms conveys social and behavioral expectations so as to ease 
communication anxiety and enable participation. Setting an agenda prepares participants to contribute relevant comments to the discussion. The referring function helps to set up the context, provide the discussion materials, and familiarizes the participants with the background of the topic of discussion. In this phase, recognition is also essential for providing the participants with social support so that they feel welcome and that their initial contributions are valued. Assessing may also be performed in this phase to gather information about participants' backgrounds, their learning preference, or their prior knowledge of the subject matter. This can be done through online polling, surveys, or questionnaires.

A number of functions are applicable in the multi-logue phase. Referring, recognition, prompting, assessing, and meta-commenting are frequently employed. Recognition and prompting are probably the most exercised functions. Recognition fulfills a social and communicative role similar to responding to a raised hand in the classroom. Prompting stimulates the next move or contribution and also helps learners to move from one zone of proximal development to the next. These two functions often go in pairs: the moderator first recognizes a contribution and prompts the student to advance a step further. Assessing in this phase diagnoses misconceptions and measures learning progress through quizzes, exams, or online review sessions. Weaving is a key function performed from time to time to ground the communication and put order in the discussion by synthesizing the accomplishments of the group.

Weaving is the most important function performed in the last phase of engaged collaborative discourse. It gathers the participants on the established common ground and builds consensus around decisions or resolutions on discussion topics. Assessing in this phase is often summative.

Two meta functions-meta-commenting and delegating-are useful throughout. Meta-commenting is called for whenever there is a weak link in communication or any threat of breakdown due to misunderstandings or uncertainty about norms. Common problems include running on too long or getting off track, failing to provide the necessary evidence of understanding, falling silent, or flaming. Besides fixing communication problems, meta-comments can solicit criticisms and complaints in order to anticipate and resolve problems before they get out of hand. The delegating function is used at any stage to assign students to take over some of the moderating functions. Students can be asked to write weaving comments or introduce topic raisers, or subconferences can be created with students as moderators. When the exercise of moderating functions is shared among students, conversations tend to be more engaging and result in more learning taking place (Xin, 2002). 


\section{Further Studies}

This article proposes a theoretical construct of the dynamics of engaged collaborative discourse in educational computer conferencing. Our goal is to contribute to an understanding of those practices of online teachers and students that are particularly effective in achieving pedagogical goals such as critical thinking and conceptual change. Future work will be carried out in multiple areas.

First, the model itself needs further elaboration and testing. Analytic tools for studying and evaluating educational conferences must be developed.

Second, the robust body of literature in discourse analysis and earlier studies on classroom talk have produced valuable insights into learning and instruction. We need to apply these insights further to the online educational experiences.

Third, this research has been carried on in conjunction with the development and testing of new software designs for asynchronous online discussion (Xin \& Feenberg, 2002). The software prototype TextWeaver is available at http:/ / www.textweaver.org. A new tool, Marginalia, inspired by TextWeaver is available at http://www.geof.net/code/annotation. These designs support moderating functions and interactivity to improve the ability of teachers and students to work together online. We are confident that further theoretical and practical work will prove mutually enriching.

\section{Acknowledgments}

This article was prepared under a grant from the Fund for the Improvement of Post-Secondary Education of the United States Department of Education. The views expressed are ours and not necessarily theirs. It is based on Xin (2002), available at http://www.textweaver.org/xin_dissertation.pdf.

We thank Norm Friesen, Edward Hamilton, and Peter Kandlbinder for their useful criticism of an early draft of this article. In addition, we thank the Editors and reviewers of the Canadian Journal of Distance Education for their ideas and suggestions.

\section{References}

Anderson, T., Rourke, L., Garrison, D.R., \& Archer, W. (2001). Assessing teaching presence in a computer conferencing environment. Journal of Asynchronous Learning Networks, $5(2)$.

Berge, Z.L. (1995). Facilitating computer conferencing: Recommendations from the field. Educational Technology, 15(1), 22-30.

Bruffee, K.A. (1999). Collaborative learning: Higher education, interdependence, and the authority of knowledge (2nd ed.). Baltimore, MD: Johns Hopkins University Press.

Burbules, N.C. (1993). Dialogue in teaching: Theory and practice. New York: Teachers College Press.

Clark, H., \& Schaefer, E.F. (1989). Contributing to discourse. Cognitive Science, 13(2), 259-294.

Dewey, J. (1938). Experience and education. New York: Touchstone. 
Feenberg, A. (1989). The written world. In R. Mason \& A. Kaye (Eds.), Mindweave: Communication, computers, and distance education (pp. 22-39). Oxford, UK: Pergamon Press.

Feenberg, A. (June, 2000). Online pedagogy with discussion management software. Paper presented at the American Association of University Professors Annual Meeting, Washington, DC.

Feenberg, A., \& Xin, M.C. (2002). A teacher's guide to moderating online discussion forums: From theory to practice. Available: http:/ / www.textweaver.org/modmanual4.htm

Feenberg, A., \& Xin. M. (2003). Facilitation. In A. DiStefano, K.E. Rudestarn, \& R. Silverman (Eds.), Encyclopedia of distributed learning. Available: http:/ / www.textweaver.org/facilitation.htm

Gadamer, H.-G. (1982). Truth and method. New York: Crossroads.

Garrison, D.R. (1991). Critical thinking and adult education: A conceptual model for developing critical thinking in adult learners. International Journal of Lifelong Education, 10(4), 287-303.

Garrison, D.R., Anderson, T., \& Archer, W. (2001). Critical thinking, cognitive presence, and computer conferencing in distance education. American Journal of Distance Education, 15(1).

Garrison, D.R., \& Archer, W. (2000). A transaction perspective on teaching and learning: A framework for adult and higher education. Amsterdam: Pergamon.

Goffman, E. (1961). Encounters. New York: Bobbs-Merrill.

Goodwin, C., \& Heritage, J. (1990). Conversation analysis. Annual Review of Anthropology, 19, 283-307.

Gunawardena, C.N. (1995). Social presence theory and implications for interaction and collaborative learning in computer conferences. Paper presented at the fourth international conference on computer assisted instruction, Hsinchu, Taiwan.

Gunawardena, C.N., \& Zittle, F. (1997). Social presence as a predictor of satisfaction within a computer mediated conferencing environment. American Journal of Distance Education, 11(3), 8-26.

Gunawardena, C.N., Lowe, C.A., \& Anderson, T. (1997). Analysis of a global online debate and the development of an interaction analysis model for examining social construction of knowledge in computer conferencing. Journal of Educational Computing Research, 17, 395-429.

Hamilton, E., \& Feenberg, A. (in press). The technical codes of online education. Techne.

Herring, S. (1996). Computer-mediated communication: Linguistic, social and cross-cultural perspectives. Pragmatics and Beyond Series. Amsterdam: John Benjamin.

Herring, S. (1999). Interactional coherence in CMC. Journal of Computer-Mediated Communication, 4(4). http://wwww.ascusc.org/jcmc/vol4/issue4/hearring.html.

Hiltz, S.R., \& Turoff, M. (1978 \& 1993). The network nation: Human communication via computer. Cambridge, MA: MIT Press.

Hutchins, E. (1991). The social organization of distributed cognition. In L.S. Resnick, J.M. Levine, \& S.D. Teasley (Eds.), Perspectives on socially shared cognition (pp. 283-307). Washington, DC: American Psychology Association.

Kanuka, H. (2005). An exploration into facilitating higher levels of learning in a text-based internet learning environment using diverse instructional strategies. Journal of Computer-Mediated Communication, 10(3). Available: http:/ /jcmc.indiana.edu/vol10/issue3/kanuka.html

Kanuka, H., \& Kreber, C. (1999). Knowledge construction in the virtual classroom. Paper presented at the 18th National Conference of the Canadian Association for the Study of Adult Education, Sherbrooke. Retrieved February 13, 2005, from: http:/ / www.oise.utoronto.ca/CASAE/cnf99/kanuca.htm

Kitcher, P. (1993). The advancement of science. New York: Oxford University Press. 
Kozulin, A. (2003). Psychological tools and mediated learning. In A. Kozulin, B. Gindis, V.S. Ageyev, \& S.M. Miller (Eds.), Vygotsky's educational theory in cultural context (pp. 15-38).

New York: Cambridge University Press.

Levinson, S.C. (1983). Pragmatics. New York: Cambridge University Press.

Lipman, M. (1991). Thinking in education. Cambridge, UK: Cambridge University Press.

Lynch, M. (1993). Scientific practice and ordinary action. Cambridge, UK: Cambridge University Press.

Mazur, J. (2003). Conversation analysis for educational technologists: Theoretical and methodological issues for researching the structures, processes, and meaning of on-line talk. In D.H. Jonassen (Ed.), Handbook of research for educational communications and technology: A project of the Association for Educational Communications and Technology (pp. 1073-1098). Mahwah, NJ: Erlbaum.

Merrill, D. (1992). Constructivism and instructional design. In T.M. Duffy \& D.H. Jonassen (Eds.), Constructivism and the technology of instruction (pp. 99-114). Mahwah, NJ: Erlbaum.

Newman, D.R., Johnson, C., Cochrane, C., \& Webb, B. (1997). Evaluating the quality of learning in computer supported co-operative learning. Journal of American Society for Information Science, 48(6), 484-495.

Oatley, K. (1991). Distributed cognition. In H. Eysenck, A. Ellis, E. Hunt, \& P. Johnson-Laird (Eds.), The Blackwell dictionary of cognitive psychology (pp. 102-107). Oxford, UK: Blackwell.

Pea, R. (1993). Practices of distributed intelligence and designs for education. In G. Salomon (Ed.), Distributed cognitions: Psychological and educational considerations (pp. 47-87). Cambridge, UK: Cambridge University Press.

Rourke, L. (2000). Operationalizing social presence in asynchronous, text-based computer conferencing. Paper presented at the Canadian Association of Distance Education (CADE) annual conference, Quebec City.

Rourke, L., Anderson, T. Garrison, D.R., \& Archer, W. (1999). Assessing social presence in asynchronous, text-based computer conferencing. Journal of Distance Education, 14(2), 51-70.

Roschelle, J. (1996). Learning by collaborating: Convergent conceptual change. In N.J.M.T. Koschmann (Ed.), CSCL: Theory and practice of an emerging paradigm (pp. 209-248). Mahwah, NJ: Erlbaum.

Rossman, M. (1999). Successful online teaching using an asynchronous learner discussion forum. Journal of Asynchronous Learning Networks, 3(2).

Stalnaker, R.C. (1978). Assertion. In P. Cole (Ed.), Syntax and semantics: Pragmatics 9 (pp. 315-332). New York: Academic Press.

Vygotsky, L.S. (1962). Thought and language. Cambridge, MA: MIT Press.

Vygotsky, L.S. (1978). Mind in society: The development of higher psychological processes. Cambridge, MA: Harvard University Press.

Wood, D. (1999). Teaching the young child: Some relationships between social interaction, language and thought. In P. Lloyd \& Fernyhough (Eds.), Lev Vygotsky: Critical assessments (vol. 3, pp. 259-275). London: Routledge.

Xin, M.C. (2002). Validity-centered design for the domain of engaged collaborative discourse in computer conferencing. Unpublished doctoral dissertation, Brigham Young University.

Xin, M.C., \& Feenberg, A. (2002). Designing for pedagogical effectiveness: Text Weaver. Paper presented at the Hawaii International Conference of System Sciences, IEEE.

Cindy Xin is a Program Director at the Learning and Instructional Development Center of Simon Fraser University. She has been conducting research and development in online learning for the past 10 years and has done work for TeleLearning Network of Centres of 
Excellence and the United States Department of Education. She is currently a member of a team that develops open-source technologies for improving online discussion forums. She can be reached at cxin@sfu.ca.

Andrew Feenberg holds a Canada Research Chair in Philosophy of Technology in the School of Communication of Simon Fraser University. He is the author of Critical Theory of Technology (Oxford University Press, 1991), Alternative Modernity (University of California Press, 1995), Questioning Technology (Routledge, 1999), and Heidegger and Marcuse (Routledge, 2005). He is also recognized as an early innovator in the field of online education. He was a member of the team that created the first online program in 1982 at the Western Behavioral Sciences Institute in La Jolla, California. He has done research on online education and online community for the US Department of Education and the National Science Foundation and is currently directing a project for improving software for online discussion forums. He can be reached at feenberg@sfu.ca. 